\title{
SEP 81965
}

\section{Cod Dnso}

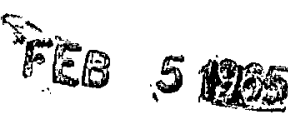

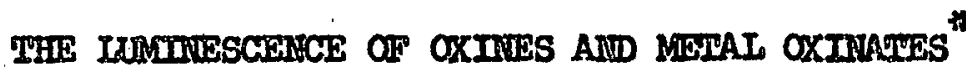

\section{Dinesh C. Bhatnagar and Ieslle S. Rorster}

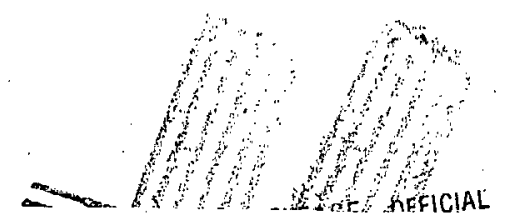

This paper was submitted for publication in the open literature at least $f /$ months prior to the issuance date of this Microcard. Since the U.S.A.E.C. has no evidence that it has been published, the paper is being distributed in Microcard form as a preprint.

$7 / 1 / 1 / 1 / 5$
Department of Chemistry

University of Arizona

Tucson, Arizona

\section{ITHERODUCTION}

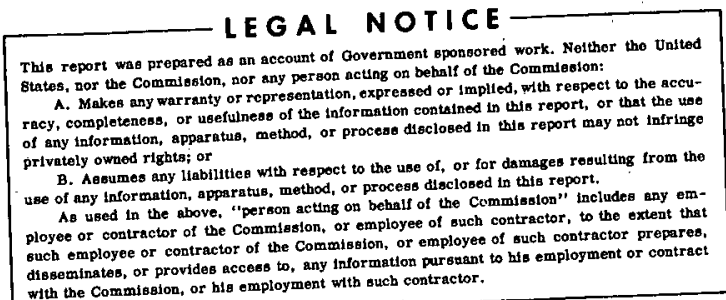

The 8-quinolinols (oxines) and thelr sulfur and selenium

analogs are useful molecules for the evaluation of the dependence of Iuminescence efficiency upon structure. A wide variety of molecules can be studied as neutral species, anjons and cations. stable metal complexes with diverse central lons may be prepared. Several studies Involving these molecules have been reported $[1,2]$. In the previous work an increase in the guantum yield of luminescence was observed with a reduction in temperature but quantitative results at low temperaivure vere not obtained. In the present study, the yields rere measured at $80^{\circ} \mathrm{K}$ where dissipstive processes with appreciable activation energies were absent. In this way the effect of structure on the rediationless processes from the low vibrational levels of the excited states may be evaluated.

\section{EXPERTHATHLAL}

The Juminescence quantum yields were measured with a spectroIlworometer previously described $[3]$. The wave length dependence of the monochromator-photomultiplier response wss determined by means of a Xenon 


\section{DISCLAIMER}

This report was prepared as an account of work sponsored by an agency of the United States Government. Neither the United States Government nor any agency Thereof, nor any of their employees, makes any warranty, express or implied, or assumes any legal liability or responsibility for the accuracy, completeness, or usefulness of any information, apparatus, product, or process disclosed, or represents that its use would not infringe privately owned rights. Reference herein to any specific commercial product, process, or service by trade name, trademark, manufacturer, or otherwise does not necessarily constitute or imply its endorsement, recommendation, or favoring by the United States Government or any agency thereof. The views and opinions of authors expressed herein do not necessarily state or reflect those of the United States Government or any agency thereof. 


\section{DISCLAIMER}

Portions of this document may be illegible in electronic image products. Images are produced from the best available original document. 
Iamp and Bausch and Lomb $250 \mathrm{~mm}$. monochromator combination calibrated by means of a Rinodamine B quantum counter $[4]$ Prom 3000-5200 \& and a therropile from 5000-9000 \&. The emission spectra are very broad and the peak maxima quite sensitive to this calibration. Agreement with published date is generally ratber good $[1]$, but discrepancles of 8 mp would not be unexpected.

A.l. quantum ylelds wexe measured with 3660 \& excltation and are computed relative to quinine bisulfate in $0.1 \mathrm{~N} \mathrm{H} \mathrm{SO}_{4}(\Phi=0.55)$. Samples were dissolved in $95 \%$ ethanol and the emission spectra detexuined as a function of tenperature. At least three determinations at different concentrations were made for each compound. The removal of aix from solutions. of 8mquinolinol and the aluminum chelate is without effect upon the quantum yield. Hon-degassed samples were used in the remainder of the work. The free 11 gends were obtained commercialiy and recrystallized from ethanol. The purification of the metel chelates is often rether difficult and we obtained quite pure materials from the research group of Dro. H. Fredsex and Q. Fexmando. Except where noted the bis complexes were thermogravimetricaliy. analyzed and particuiar care was taken to remove. water and "extra" moles of IIgand (free or coordinated). Whe tris chelates were analyzed for nitrogen content.

\section{RESUIMS - FRRE ITEATDS}

\section{Heutral. Iigands}

Whe emission spectrun of an 8-quinolinol solution at several temperatures is shown in rig. 2. At room temperature the very weak fluorescence enission occurs at longer wave lengths than enticipated from the absorption apectron. As the tempersture is reduced this weak 
band is somewhet intensifled but a band at shorter vave lengths appears. Finally, this higher energy trensition, which wirrors the absorption spectrum and resembles the expected fluorescence band, doninates the spectrum. The spectra indicate the presence of two species, one being the "normal" neutral molecule. Absorption bands in the 400-500 mu region of the apectra of 8-quinolinol, quinoline-8-thiol (thiooxine), and quinoline-8-8elenol (selenooxine) have been ascribed to zwitter-10ns. Support for this intero pretation comes Irom temperature dependence of the 0-methyl-8-quinolinol emission spectrum. No zritter-ions can be forned in this case and the spectrum consists of only one band at all temperatures.

The luminescence yields are listed in Table Io In all cases reported in this paper, when the quantum yield exceeds 0.05 the low temperam ture IImiting yield. Is reached ebove $80^{\circ} \mathrm{K}$. When the quantum yield is less than 0.05 thls limiting yleld is not obtained and these smaller yields may be Iow by as mich as $25 \%$.

Typical absorption and emission spectre are shown in Fig.2.

\section{Anions and Cations}

Zritter-ion formation is not possible in the cationic and anionic speciea derived from the neutral ligands by proton addition or removel. The fluorescence spectra are more intense at lowex temperature but no Iong wave length band is observed. The band maxima are blue abifted as the temperature is decreased, a phenomenon thich wa be related to the forms tion of a rigid glass $[6]$. In any event the observed behavior is consistent with the presence of only one species in solutions of these Lons and is consistent with zaitter-ion interpretation discussed above.

In all cases attempts to observe phosphorescence were vnsuccessful. 
Comparison of tine quantum yields of the neutral molecules with those of the anlons and cations (Tables II and III) reveals no apparent pattern. In some cases protonation reduces the yleld while in others an increase is observed. In only one case, 2amethyl-8-quinoline, does removal of a proton reduce the quamtum yield.

\section{RESUTISS - MFIAL COSTIEXES}

The results obtained for a muber of metal complexes with various 8-quinolinols are shown in Table IV. The chelation of the oxinate antons with Zn(II) produces only gell changes in quanturi ylelds. Thus, the effect of charge is rather gmall. A pronounced reduction in the thiooxinate yield accompenies chelation with zinc. The chelation of a transition metal ion results in a very marked dimimution of the luminescence yield.

With Fb(oxinate) 2 a second band appears which may be due to Iigand phosphorescence.

An interesting phenomenon is observed with the Cr(III) complexes. In Cr(osinate) 3 only the ${ }^{2} \rightarrow{ }^{4} A_{2} \operatorname{Cr}(I I I)$ Iuminescence is present, but in $\operatorname{Cr}(5,7 \text {-dibromooxinate })_{3}$ only ligen fluorescence occurs.

The substitution of sulfur and selenium Por the oxjgen in oxingte results in a progressive reduction in the luminescence yield.

A surprising dependence of the enission spectrum with excitation wave lengich (365 and $323 \mathrm{m \mu}$ ) has been reported for the oxinates of Cu(II), Fo(II), $\mathrm{Mg}$ (II), and Cd(II) [I]. We have sound no comparable behavior in the carefully purified Cu(oxinate) 2 but a similar wave length effect is observed in the less pure $\mathrm{Fb}(I I), \mathrm{Hg}(\mathrm{II})$ and $\mathrm{Cd}(\mathrm{II})$ complexes, However, the relative emission intensities axe not the same as those previously observed. The coordination of extra moles of ligand has been observed [?] and this 
coorilnation may perturb the ligand sufficiently to shift the emission maximm from the free ligand position. It is quite clear that the wave length effect is due to impurities and does not indicate emission from higher excited states.

\section{DISCUSSION}

The most striking regularity in the results is the effect of transition metal ions. Thus, the effect of metal ion on the Iuminescence yield may be small as in the case of $\mathrm{zn}$ (II) or large, $e_{\circ} g_{\circ}$, transition metal ions. One characterist1c shared by the transition metal ions employed in this work, $\operatorname{Min}($ II), $\mathrm{CU}$ (II), $\mathrm{NI}$ (II) and $\mathrm{Cr}$ (III) is the presence of metal Ion energy levels ( $\alpha-\alpha$ transitions) below the lowest singlet and. triplet levels of the 1igands. These provide a pathway for non-radiative removal of the excitation energy.

The absence of $\operatorname{Cr}\left(\right.$ III) $\mathcal{Z}_{\mathrm{I}} \rightarrow{ }^{4} \mathrm{~A}_{2}$ emission from $\operatorname{Cr}(5,7 \text {-dibromooxinate })_{2}$ is the one observation that does not fit this explanation. The ${ }_{\mathrm{E}} \rightarrow{ }^{4} \mathrm{~A}_{2}$ emission is vexy reak in $\mathrm{Cr}$ (oxinate) $3^{\circ}$ The bromination of chromium acetylacetonate reduces the luminescence yield $[3]$. A comparable effect in $\operatorname{Cr}(5,7 \text {-dibromooxinate })_{3}$ would reduce this metal emission below a detectable level. 
Thission of Jeutral Ligands at $80^{\circ} \mathrm{K}$

(95\% Ethanol Solution)

$$
\widetilde{\nu}_{\max }\left(\mathrm{cm}^{-1}\right)
$$

Coimpounds

oxine

5-chlorooxine

5,7-afchlorooxine

5,7-dibromooxine

5,7-dilodooxtne

2-methyloxine

4-methylozine

5-isoquinolinol

0-Mfe-8-quinolinol
Absorption $\left(300^{\circ} \mathrm{K}\right)$

32,250

30,300

30,600

30,853

29,650

32,800

32,050

30,600

22,600

21,750
$\Phi$

0.28

0.32

0.12

0.062

0.008

0.54

0.25

0.13

0.55 
mission of Anions at $80^{\circ} \mathrm{K}$

$$
\widetilde{\nu}_{\max }\left(\cos ^{-1}\right)
$$

Anion

Absorption $\left(300^{\circ} \mathrm{K}\right)$

Emission

$\underline{\Phi}$

oxinate

27,400

20,600

0.28

5-eblorooxinate

26,300

20,000

0.42

5.7-dichlorooxinate

25,650

20,000

0.42

5.7-dibromooxingte

26,000

20,300

0.39

587-dilodooxinate

26,000

20,000

0.034

2-methyloxinate

28,200

20,800

0.36

4-methyloxinate

$27,4.00$

21,100

0.50

5-18oquinolinolate

20,400

22,600

0.57

thlooxinate

26,000

18,900

0.023 
TABLE IIII

Emission of cations at $80^{\circ} \mathrm{K}$

$\widetilde{\nu}_{\max }\left(\mathrm{cm}^{-1}\right)$

Cation

8-quinolintum

5-chloroquinolinium

5,7-dichloroguinolinfum

5,7 dibxomoquinolinium

5,7-d1lodoquinolinium

2-methylquinolinium

4-methysqquinolinium

5-isoguinoliniuma
Absorption (300 K)

27,800

26,300

27,050

26,950

29,700

29,400

27,600

27.400
Emission

20,800

19,800

17.900

19,500

20,200

20,800

21,300

22,400
$\Phi$

0.043

0.026

0.054

0.015

0.008

0.13

0.33

0.54 
Emission of Metral Complexes at $80^{\circ} \mathrm{K}$

$$
\tilde{\mathcal{\nu}}_{\max }\left(\mathrm{cm}^{-1}\right)
$$

\begin{tabular}{|c|c|c|c|}
\hline Chelate & bsorption $\left(300^{\circ} \mathrm{K}\right)$ & Emission & $\Phi$ \\
\hline $2 n(\text { oxinate })_{2}$ & 26,650 & 19,900 & 0.32 \\
\hline Mn(oxinate) $)_{2}$ & 26,050 & 20,200 & 0.015 \\
\hline cu(oxcinate) 2 & 25,800 & 21,000 & 0.012 \\
\hline $\operatorname{ca}(\text { oxinate })_{2}^{a}$ & 26,650 & 19,700 & 0.21 \\
\hline Fo (oxinate) ${ }_{2}^{a}$ & 26,000 & $\begin{array}{l}19,900 \\
16,200\end{array}$ & $\begin{array}{l}0.013 \\
0.005\end{array}$ \\
\hline Hg(oxinace) ${ }_{2}^{2}$ & 27.050 & 29,600 & 0.11 \\
\hline Ni(oxinate) ${ }_{2}^{a}$ & 26,2110 & not detected & 0.001 \\
\hline Alloxinate $)_{3}$ & 26,810 & 20,490 & 0.30 \\
\hline$C x(\text { osinate })_{3}$ & 24,690 & 13,230 & 0.0033 \\
\hline $\mathrm{za}(5,7 \text {-dibromooxinate })_{2}$ & 25,000 & 29,600 & 0.25 \\
\hline $\sin (5,7 \text {-dibromoossinate })_{2}$ & 25,150 & $20 ; 500$ & 0.010 \\
\hline $\operatorname{Cx}(5.7 \text { adibromooxinate })_{3}$ & 25,320 & 20,750 & .021 \\
\hline $2 n(5,7 \text {-disodooxinate })_{2}$ & 24.500 & 19.500 & 0.025 \\
\hline $\ln (5,7-\alpha i \text { iodooxfinate })_{2}$ & 24,700 & 21,400 & 0.005 \\
\hline $2 n(2 \text { methyloxingte })_{2}$ & 26,450 & 20,000 & 0.35 \\
\hline $\operatorname{Mm}(2-\text { metbujoxinate })_{2}$ & 26,000 & 20,200 & 0.020 \\
\hline $\operatorname{zn}(4 \text { methyloxinate })_{2}$ & 24,300 & 20,000 & 0.45 \\
\hline Nen(4-methyloxinate) 2 & 26,000 & 20,500 & 0.035 \\
\hline $\operatorname{Zn}(\text { th1ooxinate })_{2}$ & 25,300 & 19,500 & 0.007 \\
\hline $\mathrm{Zn}(\text { selenooxinate })_{2}$ & 24,700 & 20,200 & 0.003 \\
\hline
\end{tabular}

a. Way contain some Ixee ligand.

b. $\sum_{E} \rightarrow{ }^{4} \mathrm{~A}_{2} \mathrm{Cr}(\mathrm{III})$ mission. 


\section{REAFIDATETCOS}

Supported by the U.S. Atomic Energy Combsaton.

[1] WoE。 Onnesorge and I.B. Rogers, Spectrochin. Acts 14.27 (1959).

[2] 0. Popovych and Io.B. Rogers, Spectrochim. Acta 16, 49 (1960).

[3] Ko DeArwond and IoS. Forster, Spectrochim.Acte 19, 1687 (1963).

[4] W. Melriugh, Jo Opt. Soc. Amer。 22,1256 (1962).

[5] D. Sekido, Q. Fernando, and y. Freiser, Anal. Chem, 36, 1768 (1964).

[6] M.I. Bhaumik and R. Hardwick, Jo Chem. Fhys. 32, 1595 (I963).

[7] F. Chou, Q. Fernendo, and H. Frejser, Ansl. Chem.s in press. 


\section{IEGMADS}

Fisf. 1 Spectra of 8-quinolinol

$$
\text { (a) } 80^{\circ} \mathrm{K},(\mathrm{b}) 180^{\circ} \mathrm{K}, \text { (c) } 300^{\circ} \mathrm{K} \text { 。 }
$$

The spectra are not corrected for wave length veriation of instrument seasitivity. The relative intensities in differemt spectra are not meaningiul.

Fig. 2 Absorption ( $\left.300^{\circ} \mathrm{K}\right)$ and emisston spectra $\left(80^{\circ} \mathrm{K}\right.$, corrected) of 8-quinolinol and jons: $a$ and $a^{0}-8$-quinolinol; $b$ and $b^{\circ}, 8$-quinolinium cation; $c$ and $c^{0}-8$-quinolinate anion. Heither absorption nor emission intensity alferences between spectra are meaningrul. 


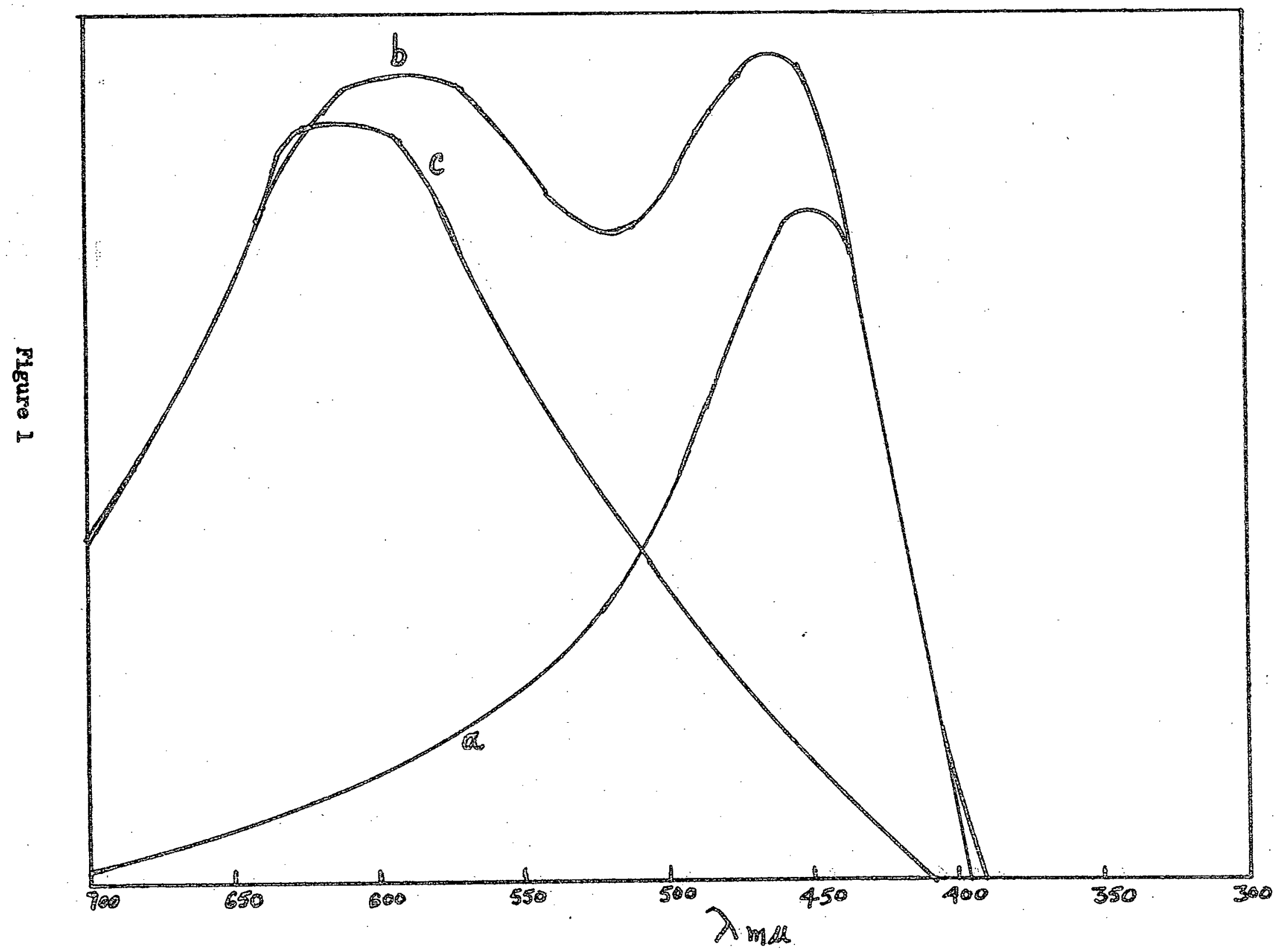




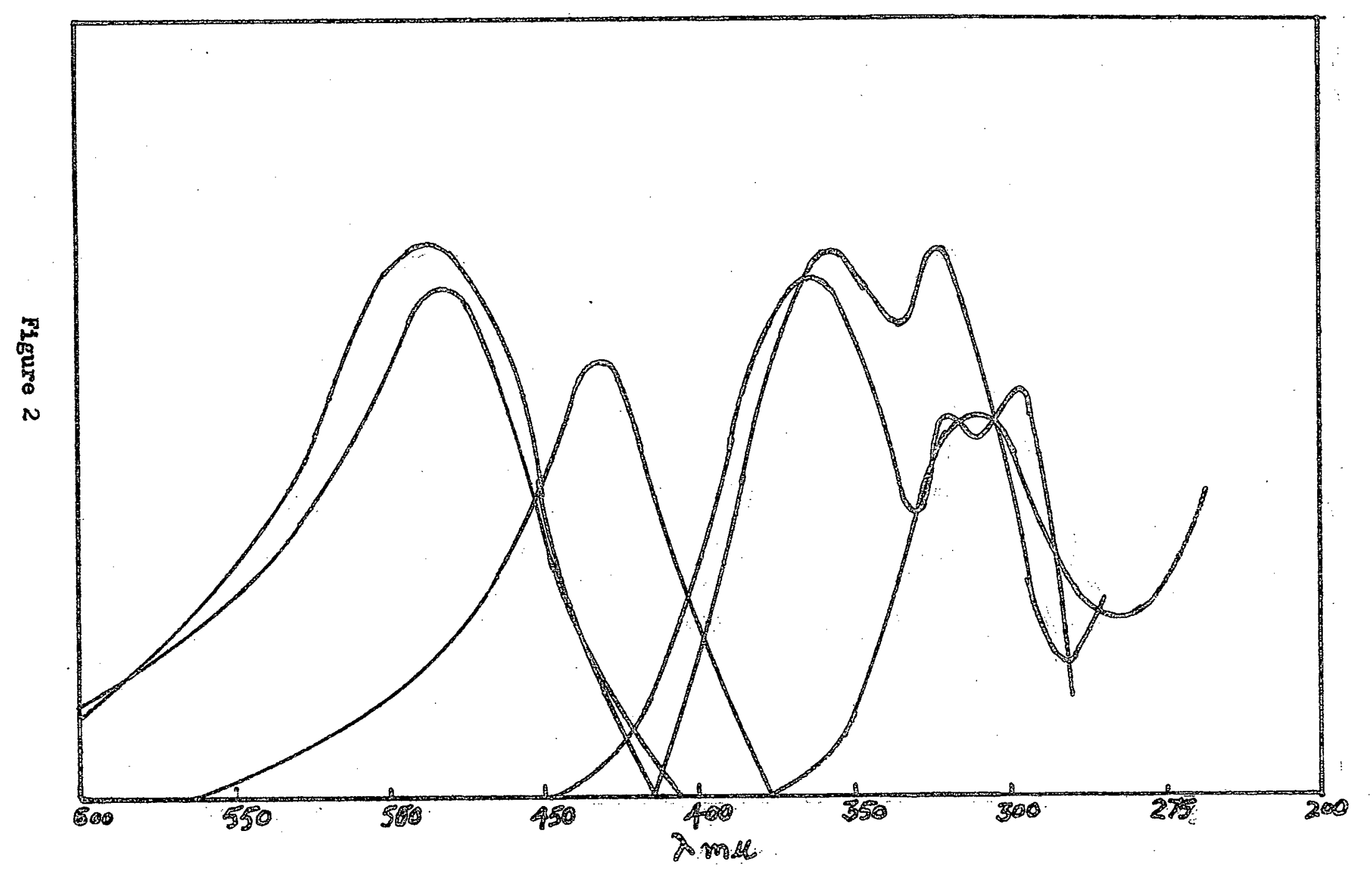

